\title{
Critical Literacy: Using Picturebooks to Read the World
}

\author{
Alexis Birner, Lindsay Bromley \\ The University of British Columbia, Vancouver, Canada
}

\begin{abstract}
In this article we develop instructional strategies that promote meaningful student engagement with literature facilitated through the use of picturebooks. A critical pedagogy, whereby learners develop skills such as questioning, critiquing, and inquiring, is necessary in order for students to succeed in the 21 st century. Such a pedagogy can be introduced to learners through a critical literacy framework, which encourages learners to recognize and analyze the social constructions present in texts. The literary environment of 21 st century students is saturated not only with print, but also with visual modes of communication. To teach students to think critically about language and texts, teachers must address both print and visual literacy. Using three classroom-tested picturebooks and activities, we show how the multimodal nature of picturebooks makes them an excellent resource to facilitate critical literacy. Using picturebooks in conjunction with a critical literacy framework will help develop the literacy skills necessary for students' active civic engagement in the 21 st century.
\end{abstract}

Keywords: picturebooks, critical literacy, multimodality, social justice, critical inquiry

\section{Introduction}

Globalization and advancements in information and computer technology have brought dramatic changes on the world. Hall (1991) describes "these transitional 'new times' as shifts in the technical organization of industrial-capitalist production towards information technologies” (Lankshear \& McLaren, 1993, p. 2). Information that was once only accessible to an educated elite can know be accessed by the majority of North Americans via the Internet and other mass media. This open access to information has extensive implications for education. The New London Group (2000) states that "radical changes are occurring in the nature of public, community and economic life... we have to rethink what we are teaching" (p. 10). This situation leads us to ask ourselves: Is education keeping pace with societal changes that bring greater access to knowledge and information? Are we teaching children to engage critically with the ever increasing plethora of ideas and knowledge available to them? What can teachers do to teach students to engage with knowledge in a critical way?

In a rapidly changing educational climate, critical thinking skills are a vital tool for students to be successful in both a wide variety of post school careers and for active civic engagement. The New London Group (2000) states:

If it were possible to define generally the mission of education, it could be said that its fundamental purpose is to ensure that all students benefit from learning in ways that allow them to participate fully in public, community, and economic life. (p. 9)

Alexis Birner, MEd, The Department of Language and Literacy Education, The University of British Columbia. Lindsay Bromley, MEd, The Department of Language and Literacy Education, The University of British Columbia. 
The challenge of teaching students to think critically and become sophisticated users of information is compounded by increasing levels of sociocultural diversity in the classroom. As teachers inculturally and economically diverse schools in a metropolitan city, we recognize that the current methods and foci of education need to be reconsidered. In order to create learning conditions in which every student can participate fully, issues of difference from majority groups become critically important. As teachers, how can we address the necessary 21 century literacy skills of our students, while also fostering the diversity of non-majoritarian groups?

To engage students from diverse backgrounds in our classrooms, while also addressing the changing nature of work and knowledge, teachers need to take a critical approach to teaching and student learning. One framework to address these needs is a critical literacy framework. To that end, we propose and have developed a conception of critical literacy that can be applied in elementary classrooms using picturebooks. The term " 21 century learning" echoes thoughts of technology; however, traditional resources, such as picturebooks, can also be central to developing critical literacy skills. The picturebook gives children the opportunity to function across modes of communication, particularly visual communication. Making meaning through visual images, in addition to the print, is an essential literacy skill in the 21 century, and picturebooks support this multimodal learning. Unsworth (2001) states:

$[T]$ he parameters of school literacies have been significantly extended with the rapid cultural and technological changes on literate forms of communication in recent years. Predominant among these are the growing impact of images in an increasing range of texts. (p. 1)

This paper will serve as a useful tool for teachers looking to address the needs of 21 century learning. We create a teaching framework for developing critical literacy skills and this framework is facilitated through the use of picturebooks. While there is a significant amount of theory regarding critical pedagogy in education (Morgan, 1997; Lankshear\& McLaren, 1993; McLaren, 2003), there are minimal resources available to help elementary teachers apply a critical framework to their teaching practice. This work seeks to bridge the gap between research and practice in critical literacy. Our review of existing theory and research will make critical literacy accessible to all teachers, and the teaching applications we develop will assist in implementing critical literacy in elementary school classrooms.

\section{Definition of Terms}

Many of the terms in this paper are widely used in educational discourse. Depending on the theoretical frames of the users, these key terms can vary in definition. To situate our understood meanings of some key terms in our paper, we will explicitly outline our definitions.

Critical literacy is the act of consciously deconstructing texts to reveal and critique taken-for-granted social norms. Critical literacy is not simply a set of skills, knowledge, or the ability to read, write and develop aural skills (Giroux, 1993, p. 368). Critical literacy practices involve a critical reading of social constructions present in the world. Therefore, critical literacy involves actively questioning socially constructed beliefs, and renegotiating power hierarchies embedded in language. By gaining control over language, marginalized students can be empowered, and classroom structures that perpetuate undemocratic life can be transformed (Gee, 1992; Lankshear \& McLaren, 1993; Vasquez, 2010).

Texts are socially produced forms of communication, including but not limited to written print, visual 
images, gesture, and body language (Vasquez, 2010). This understanding of texts extends beyond books and other traditional print-based materials. As Vasquez (2010) states, "[t]he world is a socially constructed text that can be read" (p. 3).

Picturebooks fall under the genre of children's literature. Our definition of a picturebook highlights the integration of both image and word in order to convey overall text meaning (Nikolajeva, 2003; Nodelman, 1988). A picturebook requires the reader to make meaning from both modes of communication, without emphasis of one mode over the other. While the picturebook genre includes many categories such as information books, wordless picturebooks, and illustrated stories (this list is not exhaustive), our definition of picturebooks will be limited to those whereby a fictional narrative is told through images and words (Nikolajeva, 2003).

Multimodality is a field of study that focuses on "how human beings use different modes of communication, like speech, writing, image, gesture, and sound, to represent or make meaning in the world" (Stein, 2008, p. 871). Adopting a multimodal approach to reading picturebooks, teaches students to read across these multiple modes of communication.

\section{Background Theory}

Theory in critical literacy began with Paolo Friere, a Brazilian educator. His book, Pedagogy of the Oppressed (1970), outlines his message that educational institutions need to be places of transformation and liberation for all, and be a place to deconstruct the power imbalances embedded within language. In order for students to transform their world, Freire identified the skills of inquiry, creativity, critical thinking, reflection and action as being central to a critical teaching pedagogy. At the heart of all these skills is language, and Freire argued that language is a tool that can be used to empower learners.

Subsequent critical literacy theory emerged out of Freire's conceptualization of schools as a place to create critical awareness of the structures and systems that regulate and perpetuate power imbalances. More currently, theorists such as Giroux (1993) also recognize that the place to take up the unequal distribution of power in language was through critical pedagogy in formal schooling. Critical pedagogy in a classroom context should specifically look at how and why knowledge becomes constructed the way it does, and to question why some constructions of meaning are legitimized and endorsed by the dominant culture, while others are clearly not. McLaren (2003) adds to this notion, and remarks that knowledge acquired in school, or elsewhere, is never neutral, but is structured in a manner that reflects particular power relations found within society; therefore, an important function of teaching critical theory is recognizing that knowledge is a social construction.

One manner of taking control over knowledge is by helping students obtain the necessary critical literacy skills to question issues of power and hierarchy. Lensmire (2001) states, "[g]oals of critical pedagogy are to empower students to engage in this social struggle over meaning" (p. 105). Applying a critical lens to literacy practices in schools helps assist students in breaking down socially constructed levels of power through language. Critical pedagogy is concerned with students becoming active participants in the construction of their worlds, rather than remaining trapped in the meanings, subjectivities, and forms of authority determined by more powerful others (Lankshear \& McLaren, 1993). Giroux (1993) states that educators need to organize the curriculum in a way which allows students to critique and make judgments about "how society is historically and socially constructed, how existing social practices are implicated in 
relations of equality and justice, as well as how they structure inequalities and racism, sexism, and other forms of oppression" (p. 374).

While some educators may question whether or not elementary school children are ready to engage in such critical pedagogy, research and theory suggests that there is no better place for such a framework than in an elementary school classroom (Vasquez, 2010). Vasquez (2010), a prominent critical literacy teacher-researcher, notes that in her work with elementary school children, the students have unfailingly proven that they "are in fact very capable and willing to participate in [deep] conversations which are meaningful to them, and impact their lives" (p. 6). Teachers cannot afford for children not to engage in difficult conversations or topics if we hope for them to become critical analysts of the world that they live in, and for them to be able to make decisions regarding their place in a diverse world (Vasquez, 2010).

Drawing on the work of critical literacy theorists, we recognize that critical literacy is not a unit to be taught in isolation. Rather, a critical lens is applicable to all subjects (Vasquez, 2010). Morgan (1997) remarks that a critical framework is an instructional technique and is multidisciplinary in nature, "encompassing texts and issues found also in history, and geography and media and cultural studies" (p. 29). In addition, the cultural knowledge and multimedia literacy practices of the students need to be recognized and be authentic, as students learn best when they are learning in a meaningful way (Vasquez, 2010). Therefore, teachers need to draw on topics and issues that students raise and incorporate them into the curriculum.

While implementing a critical literacy framework with young students may seem daunting, picturebooks can act as a vehicle to bridge the gap between critical literacy theory and practice. Picturebooks, when used within a critical literacy framework, are a resource that can help students identify social constructions in text, question dominant ideologies use language to reposition power hierarchies and address the topic that are authentic to the children.

\section{Critical Literacy, Multimodality and Picturebooks}

Several theorists have identified that a true picturebook is one where the words and pictures interact in a significant way to create the overall meaning of the text (Nikolajeva, 2003; Nodelman, 1988; Sipe, 1998). As Nikolajeva (2003) points out, "when discussing picturebooks we must pay attention to how words and pictures cooperate to create a meaning" (p. 237). When using a picturebook, preference or importance cannot be given to either the words or the pictures, as it is the interaction between the words and pictures that is one of the most essential features of a picturebook. In a picturebook, if either the image or the words were to be removed, the text would not maintain meaning in its entirety.

When these visual and linguistic modes of communication are occurring simultaneously, as is the case in picturebooks, the text is said to be multimodal. As previously noted, 21 st century literacy practices require the reader to be able to function fluently across a variety of modes. Because the reader must interpret multiple modes in order to make meaning from text, teachers need to recognize and teach both modes of communication. As such, the picturebook is beneficial because it draws on two modes of communication, linguistic and visual, to address the needs of 21 st century literacy learners. Serafini (2009) states,

[p]icturebooks are multimodal, meaning that they draw upon multiple modes of expression, namely- written language, visual image and graphic design - to tell a story or offer information... in order to construct meaning... children need to attend to both systems of meaning. (p. 11) 
Like written language, visual images are embedded with social meanings that can be deconstructed; therefore, we need to teach children tocritically read across print-based and visual signs. Using picturebooks to facilitate critical literacy provides students the opportunity to perform a critical, multimodal reading of text. Critical inquiry of both the images and words is needed to truly reveal the power relations inherent in a piece of text, and a critical analysis of a picturebook asks the reader to question both the images and print as combined elements. Nikolejava (2003) views pictures as conveying ideology. Therefore, it is "all the more important to train young readers to read visual images alongside the verbal ones" (Nikolejava, 2003, p. 240). Teaching the process of critical inquiry is essential from an early age, as picturebooks are used as a learning tool from the very first years a child enters school. Some theorists have suggested that a socialization process takes place through the messages in picturebooks while using them to teach young children (J. H. Schwarcz \& C. Schwarcz, 1991). These theorists argue that children learn about the world and the values of society through messages from picturebooks. These young children are capable of deconstructing the ideology represented in this type of text when taught critical literacy skills of inquiry and questioning.

From a critical perspective, students and teachers ask what messages the images and words are presenting. Teachers may prompt students to examine whether the images and words present the same message or if there is contradiction between what they see and what they read. Nikolajeva (2003) argues that:

The text can appear fairly neutral and fairly innocent in its treatment of power structures, while images can produce an undesirable effect. On the other hand, tokenism, for instance the portrayal of an ethnic group, is more likely to appear in the visual. (p. 241)

In addition, students and teachers should question why the author is representing the world in this way, and whether the author presents viewpoints that reflect the same realities as the students' lives. By the time children have reached school, their socialization has already informed them of their personal reading of the world (Gee, 1992), and the multimodal texts we present in schools may reinforce or contradict this reading of the world. Teachers can use picturebooks as an accessible and multimodal resource for children to engage with the word and world in a critical fashion.

When selecting picturebooks for critical inquiry, we recommend that teachers apply the following three criteria as informed by critical literacy theory:

- The books are multimodal: The visuals tell the story as much as the written word, and both the visual and the words are equally important to understanding the overall text. Twenty-first century literacy practices are requiring readers to function fluently across a variety of modes.

- The books deal with social justice issues which are relevant to students in our multicultural and diverse classrooms. In order for meaningful critical discussions to take place, topics discussed must be authentic and meaningful to the students.

- The books are accessible to a range of reading abilities in diverse classrooms. Additionally, the text can be accessed at a variety of grades levels, from kindergarten through to grade 7.

While there are countless picturebooks available that meet these criteria, we have selected three which we have used in our classrooms for critical inquiry. For each book, we provide learning activities which encompass the pedagogies of critical literacy in an elementary school classroom. The following section will present activities done with the picturebooks 10,000 Dresses (Ewert, 2008), The Rabbits (Marsden \& Tan, 1998), and The Island (Greder, 2002). 


\section{Critical Inquiry Picturebooks and Activities}

Title: 10,000 Dresses

Author: Marcus Ewert

Illustrator: Rex Ray

Grades: K-7

Social Justice Issues: Gender stereotypes, transgendered youth

Plot Summary: 10,000 Dresses is the story about Bailey, a transgendered child who is biologically a boy, but identifies as a girl. Each night, Bailey dreams about making and wearing imaginative dresses. Each day, she goes to a member of her family to tell them about her dream and is chastised because they believe boys should not be interested in dresses. Finally, Bailey forms a friendship with a teenage girl (Laurel) who supports her interest in dresses, and this girl embraces Bailey's love of dresses and together they make a fantastical mirror dress.

Critical Activities: An inquiry into 10,000 Dresses will be very much determined by the needs of the class. For younger students, teachers may want to direct the learning to focus on gender roles and whether it is acceptable for boys to be interested in traditionally female interests, such as dress making and fashion. For older students, issues around transgendered youth would be appropriate, particularly if students have already begun to have conversations about LGTB people. At the heart of the story is the acceptance of oneself and of others within our community. The cover illustration will likely prompt some discussion, and is a great starting point for inquiry into the book. Show a picture of the cover of the book, and have students observe, wonder, and make inferences about the picture. This can be done orally, or written in a chart. From this discussion alone, teachers will be able to determine how strongly developed students' beliefs around gender are, and whether or not students go to the topic of gender without teacher prompting. Then, the teacher should facilitate a pre-reading discussion: Do they think it is a boy or a girl? What clues from the picture makes them think that?

The illustrations in this book are multi-faceted through the use of colour, foreground and background, and texture and detail; as such, reading the illustrations would be a great activity to do next. Teachers could make colour photocopies of the images, covering up the words. Using just the images, has students describe Bailey's emotions throughout the story, drawing their attention to where she is positioned on the page, the clothes she is wearing and her facial expressions. Teachers can facilitate inferences and questions about the pictures. The students will discover that when Bailey is being scolded by a parent, she is located in the background and dressed very minimally. When Bailey is expressing her true self (in her dreams and at the end with Laurel), she is salient in the picture and wearing eye-catching dresses. This activity encourages students to conduct to a close reading of the visuals. The words do not explicitly state Bailey's dejected response to her family's disapproval, but the pictures certainly do.

After analyzing the pictures, read the story to the class. Draw the students' attention to the way the author and illustrator use different colours for the words in this text. Focus on the repeated use of the passage, "You're a boy. Boys don't wear dresses". This line is said by each of Bailey's family members. Write this quotation on the chart paper or board and ask students where they think Bailey's family got this idea that "boys don't wear dresses". This will push the students to critically analyse what factors influence constructions of gender. In addition, it allows children to recognize there is nothing natural or inherent in our understandings of gender, and that our ideas about boys/girls are, in fact, social constructions. As a follow-up to this activity, have the 
students search through magazines, flyers, the school library, or possibly websites, and identify images that reinforce the views held by Bailey's family, such as a flyer of a woman holding a bouquet of flowers or a man working on a car.

Another activity, which would be especially useful for older students, is "Writing in Role". This provides an opportunity to give voice to typically silenced youth, such as transgendered children. It will also give children who have a difficult time empathizing with Bailey an opportunity to internalize the struggles of those who are not accepted. On the other hand, children who may be dealing with gender identity issues of their own will have the chance to have their voice heard. Post the images from the first "picture walk" activity on the board, and have the students' select one image. Based on what they see in that picture, the students will write a letter in the role of Bailey to any other member of the family. As an extension, the students could trade letters and write responses from the perspective of the family member that the letter was addressed to.

10,000 Dresses is an excellent picturebook to use in elementary school, as it can be used from kindergarten right through to grade 7. Additionally, there are a limited number of resources which address LGTB issues at the primary grade levels, specifically in the form of picturebooks.

Picturebook Title: The Rabbits

Author: John Marsden

Illustrator: Shaun Tan

Grades: 4-7

Social Justice Issues: Colonization, Aboriginal peoples, industrialization, sustainability/eco-criticism.

Plot Summary: The Rabbits is the colonization tale of a group of "rabbits" arriving in a new place and slowly taking over the land from its original inhabitants. The narration is from the point of view of one of the original inhabitants. This gripping story shows how, at first, the inhabitants were accepting of the rabbits, although the elders warned them to be wary. As the story continues, the level of industrialization, environmental degradation, and loss of power of the inhabitants perpetuates. The story of The Rabbits represents European colonization during the 18th and 19th centuries, and the original inhabitants are representative of Aboriginal people. In the story, the Aboriginal inhabitants tried to fight back but, due to the sheer number of rabbits, were powerless to stop the colonization of their land.

Critical Activities: The visual images in this book are remarkably striking. Hence, teachers could begin their critical investigations using the illustrations. The sixth open fold has an image of a massive boat, and many of the rabbits arriving on the shore. Using a process drama approach, have the students participate in a "Proximity to the Problem" activity based on this picture, taken from Perry and Medina (2011). Students should try to identify what a problem on this page might be (for example, the invasion of foreign people, or destruction of the beach, or large boat in shallow water). They can identify a problem from any perspective they choose, whether that perspective is represented on the page or not. Place a chair in the centre of the room, and have this chair represent "the problem" that each individual student has individually identified. Next, have the students embody a person, place or thing, and place themselves around the room in relation to the problem. For example, if one student identifies the problem as the destruction of the beach, and he or she embodies a shrub near the beach, he or she may place himself or herself quite close to "the problem" (the chair) because the shrub is about to be destroyed. Another student may see the problem as invasion of a new land, and may embody a colonial empire in the West. In this case, he or she would place herself or himself far away from the chair, as Western empires were physically far removed from their colonial lands. Once all students have embodied a 
perspective in relation to the problem and placed themselves around the room, ask them to share what they view as the problem and what they are embodying in relation to the problem. This activity demonstrates the multiple perspectives that can be taken from an image and the multiple voices that are connected to an image, whether or not they are actually included in the picture.

Another activity to do with this book is "Writing in Role". After reading the book, ask the students whose perspectives were represented in this book, and whose voices were minimally heard. Some students will note that because the narration is from the perspective of the native inhabitants, the rabbits' perspective has not been included. Encourage your students to think at a deeper level and look for more abstract perspectives, such as the environment or children of the inhabitants. Students can also write in the role from a perspective of something that has not been represented. Once students have chosen a perspective to embody, have them write a journal entry using the inner voice of their perspective. This activity encourages the students to look beyond an oversimplification of colonial issues into colonized and colonizer, or victim and victimizer. Issues of colonization are complex, layered, and require critical inquiry into the many perspectives that were and continue to be impacted by such events.

As always, using a critical literacy approach requires asking critical questions throughout a reading of the book. The final page of The Rabbits asks the question, "Who will save us from the rabbits?". This closing question asked by the Aboriginal inhabitants of the colonized land has great potential for critical discussions. Teachers can pose the following questions: Who is this question addressed to? What would "help" look like, and who could offer it? Is it appropriate to help these people? Would help from an outside group be similar or different to the rabbits' colonization? In order to prompt students to think beyond the context of the picturebook, have groups of students develop and present tableaux (a silent, still scene), that take place 100 years after the end of the book. Will the groups include the Aboriginal inhabitants that were colonized by the rabbits in their tableaux? Do the tableaux represent continued destruction 100 years later, or do they represent modernization and independence of the colonizing people?

The Rabbits and the writing, discussion, and process drama activities described above are best suited for grade 6 and 7 students. While the picturebook itself could certainly be read and discussed in all intermediate grades 4 through 7, the abstract nature of some of the activities and discussions would be better done by older students. If teachers work with grades 4 and 5 students on writing in role and process drama activities, the students will certainly be able to tackle more complex topics and issues. However, it is not recommended to begin these serious critical inquiries until a community of acceptance and risk-taking has been established.

Picturebook Title: The Island

Author and Illustrator: Armin Greder

Grades: 3-7

Social Justice Issues: Insider-outsider relations, xenophobia vs. acceptance and tolerance, power hierarchies and struggles, human behaviour and socialization, fear of the unknown

Plot Summary: A man's raft washes up on the shore of an island. He appears to be different to the native islanders. Initially, the islanders want to send him back to the sea, but a fisherman objects and states that they should take care of him. They decide that he is their responsibility now, so they lock him in a pen, and life on the island resumes as normal. Although he is physically away from the people, his presence creates paranoia in the community. Fueled by their own fears, the islanders drive the man back onto his raft and into the sea. They justify their actions by believing that they need to protect themselves from savages who will take away their 
jobs and food. The final page shows how the islanders burn the fisherman's boat, since he was the one who originally suggested that they take in the stranger, and then they build a large wall around the island to protect themselves from anything foreign to the island.

Critical Activities: This haunting picturebook has significant implications for how immigrants can be treated, and reflects issues of insider-outsider relations. This book is reminiscent of how the Jews were treated in Nazi Germany, how immigrants from different cultures may be treated when moving to a new country, and how fear of the unknown can lead to xenophobia. The images consist of dark, charcoal drawings which evoke emotions of anger due to the unclean lines. Additionally, the people in the book do not depict a particular race or culture. It could be anyone or any culture represented, allowing for this picturebook to be applied to many contexts.

The picturebook could be used critically in conjunction with a unit or discussion about race, acceptance or tolerance, or how minority groups are treated. Attention should be drawn to the title and cover before commencing a critical reading of the book. It is significant that the book takes place on an island, where people are already in isolation. The teacher could read the students the words without showing them the corresponding images, and have the students visualize how they imagine the illustrations to be. Share the ideas, then read the story again, this time showing the illustrations. Follow the second reading with a discussion of how the images changed the meaning of the story, and how the images add a darker, more foreboding tone to the book. Next, encourage critical thought by asking the students questions such as: What are the islanders afraid of? How does the man pose a threat? What is the wall meant to represent?

One activity to encourage deep inquiry to this picturebook is the activity "Writing on the Wall". Using large paper, the teacher can cut out the silhouettes of two people, and hang them on the board. Explain that one silhouette represents the islanders, while the other represents the stranger. As the teacher reads the book for the second time to the class, allow students to come up and write a word or phrase on either of the silhouettes that strikes them about that character. Encourage the students to write down emotions the characters may feel, or something from the voice of that character. Finally, once everyone has had an opportunity to write something, read each of the silhouettes out loud, and discuss what was written and why.

Another activity which encourages students to think critically about the behaviours of the islanders is "Gossip Mill". The teacher explains that the students are the islanders, and they have been told that the stranger has just arrived on the island. The students are then to "mill" about, and gossip about the stranger being allowed onto the island. Although none of the islanders have met the man yet, it is likely that their gossip will be negative, only perpetuating the fear of the unknown outsider. Perhaps some of the students will gossip in defence of the stranger. The teacher should make note of powerful phrases and comments made by the islanders, and later use this for critical inquiry in relation to how outsiders are represented in greater society.

The Island ends with the community erecting a massive wall around their island to prevent other "visitors" from arriving on their shores. Facilitate a discussion with the class about the pros and cons of having the wall around the island. Does the wall protect the islanders from other outsiders? How does this isolate them from interaction with the outside world? After the discussion, have the students write in role as an islander who was a child at the time that the wall was built and who is now an elder in the community (approximately 75 years later). The elder is reflecting on how their community has changed since the erection of the wall. Give such prompts as: Have there been any other encounters with the outside world? Is the community curious about the outside world? Have any community members left and not come back? 
Although this book would be appropriate for an older audience, it lends itself to many units or areas of study including the Holocaust, civil rights, tolerance, and general fear of the unknown. The powerful visual images will encourage critical discussion and, with guidance, encourage the students to reflect and question issues of insider-outsider relations, and how dominant society can maintain levels of hierarchy and fear.

\section{Conclusion and Future Implications}

Critical literacy in schools is concerned with fostering students' ability to deconstruct the power hierarchies present in texts, questioning their own positionality in the social world, and reacting to these constructions through positive change. Recognizing that the literacy environment of 21 st century students is saturated not only with print, but also with visual modes of communication requires students to make meaning across a variety of modes in order to fully participate in literacy events. The use of picturebooks in conjunction with a critical literacy framework will help to develop the new literacy skills necessary for active civic engagement for all in the 21 st century.

Although picturebooks are a useful resource to develop critical literacy skills, they should act as a stepping-stone for students to apply these critical skills to everyday texts. Once students have mastered critically interrogating dominant social constructions in picturebooks, they should practice applying these same skills to everyday texts present in their lives. It is our goal for students to eventually be able to independently apply a critical lens of questioning and critiquing to everyday texts that they encounter, particularly to digital texts - a form of literacy with which their lives are becoming increasingly saturated.

\section{References}

Ewert, M. (2008). 10, 000 dresses. New York: Seven Stories Press.

Freire, P. (1970). Pedagogy of the oppressed. London: Sheed and Ward.

Gee, J. P. (1992). The social mind: Language, ideology, and social practice. New York: Greenwood Publishing.

Giroux, H. (1993). Literacy and the politics of difference. In C. Lankshear, \& P. L. McLaren (Eds.), Critical literacy: Politics, praxis, and the postmodern (pp. 367-377). New York: State University Press.

Greder, A. (2002). The island. Duesseldorf: Allen \&Unwin.

Lankshear, C., \& McLaren, P. L. (1993). Critical literacy: Politics, praxis, and the postmodern. New York: State University Press.

Lensmire, T. J. (2001). Writing for critical democracy: Student voice and teacher practice in the writing workshop. In S. Boran, \& B. Comber (Eds.), Critiquing whole language and classroom inquiry (pp. 103-122). Urbana, IL: National Council of Teachers of English.

Marsden, J., \& Tan, S. (1998). The rabbits. Victoria, Australia: National Library of Australia.

McLaren, P. L. (2003). Critical pedagogy: A look at the major concepts. In A. Darder, M. Baltodano, \& R. Torres (Eds.), The critical pedagogy reader (pp. 69-96). London: Routledge.

Morgan, W. (1997). Critical literacy in the classroom: The art of the possible. London: Routledge.

Nikolajeva, M. (2003). Verbal and visual literacy: The role of picturebooks in the reading of young children. In N. Hall, J. Larson, \& J. Marsh (Eds.), Handbook of early childhood literacy (pp. 235-248). London: Sage Publications.

Nodelman, P. (1988). Words about pictures: The narrative art of children's picture books. Athens, GA: University of Georgia Press.

Perry, M., \& Medina, C. (2011). Embodiment and performance in pedagogy research: Investigating thepossibility of the body in curriculum research. The Journal of Curriculum Theorizing, 27(3), 62-75.

Schwarcz, J. H., \& Schwarcz, C. (1991). The picture book comes of age. Chicago, IL: American Library Association.

Serafini, F. (2009). Understanding visual images in picturebooks. In J. Evaus (Ed.), Talking beyond the page: Reading and responding to picturebooks (pp. 10-25). New York: Routledge. 
Sipe, L. R. (1998). How picture books work: A semiotically framed theory of text-picture relationships. Children's Literature in Education, 29(2), 97-108.

Stein, P. (2008). Multimodal instructional practices. In J. Coiro, M. Knobel, C. Lankshear, \& D. J. Leu (Eds.), Handbook of research on new literacies (pp. 871-898). New York: Lawrence Erlbaum Associates.

The New London Group. (2000). A pedagogy of multiliteracies: Designing social futures. In B. Cope, \& M. Kalantzis (Eds.), Multiliteracies: Learning and design of social futures (pp. 9-37). London: Routledge.

Unsworth, L. (2001). Teaching multiliteracies across the curriculum: Changing contexts of text and image in classroom practice. New York: Open University Press.

Vasquez, V. (2010). Getting beyond I like the book: Creating space for critical literacy in K-6 classrooms. Newark, DE: International Reading Association. 